\title{
Efeito da época de poda e da desfolha na interceptação de radiação solar na videira Bordô
}

\author{
André Luiz Radünz ( $\left.{ }^{1 *}\right)$; Edgar Ricardo Schöffel ( $\left.{ }^{1}\right)$; Márcia Oliveira Curi Hallal ( $\left.{ }^{2}\right)$; Gabriel Franke \\ Brixner ( $\left.{ }^{3}\right)$ \\ (') Universidade Federal de Pelotas (UFPel), Departamento de Fitotecnia, Faculdade de Agronomia, Campus Capão do Leão, \\ 96010-900 Pelotas (RS), Brasil. \\ (2) Universidade Federal de Pelotas (UFPel), Conjunto Agrotécnico Visconde da Graça (CAVG), 96060-290 Pelotas (RS), Brasil. \\ (3) Universidade Federal de Santa Maria (UFSM), Departamento de Fitotecnia, 97105900 Santa Maria (RS), Brasil. \\ (*) Autor correspondente: alradunz@yahoo.com.br
}

Recebido: 29/maio/2013; Aceito: 31/out/2013

\begin{abstract}
Resumo
O presente trabalho teve por objetivo determinar a influência da desfolha e da época da poda seca sobre o albedo e sobre a radiação solar disponível ao nível dos cachos e determinar o efeito da radiação solar sobre o acúmulo de sólidos solúveis da videira. Foram realizadas duas épocas de poda seca e a desfolha em parte do vinhedo da cultivar Bordô conduzida no sistema pérgula. A radiação solar foi medida utilizando-se tubos solarímetros instalados em cada tratamento, sendo o teor de sólidos solúveis determinado no momento da colheita, com um refratômetro de campo. A realização da poda seca exerceu influência sobre o albedo, sendo que o maior albedo da videira Bordô é observado quando a poda seca ocorreu na época normal (meados de setembro) e sem desfolha. Para o período compreendido entre a poda e a desfolha, o albedo variou entre 0,28 e 0,30. Os resultados demonstram que o adiamento da poda seca representa redução na quantidade de radiação solar disponível ao nível dos cachos, ao mesmo tempo em que a realização da desfolha propicia aumento na radiação que incide ao nível dos cachos. O acúmulo de sólidos solúveis está relacionado com a radiação solar disponível ao nível dos cachos.
\end{abstract}

Palavras-chave: sólidos solúveis totais, desfolha, sistema de condução latada, balanço de ondas curtas.

\section{Effect of pruning time and defoliation on solar radiation interception in Bordô grapevines}

\begin{abstract}
In this study, we aimed to evaluate the influence of defoliation and dry pruning time on the albedo and solar radiation available at the level of clusters and to determine the effect of the latter on the accumulation of soluble solids in grapevines. Two periods of dry pruning and defoliation in part of a Bordô cultivar vineyard grown in pergola system were carried out. Solar radiation was measured using solar meter tubes installed for each treatment. The soluble solids content was determined at harvest using a field refractometer. The dry pruning exerted influence on the albedo, while the highest albedo of the Bordô vine was observed when the dry pruning occurred in the normal season (mid-September) and without defoliation. The albedo ranged from 0.28 to 0.30 during the defoliation period. The results showed that a delay of the dry pruning represents a reduction in the amount of solar radiation available at the grape clusters, while defoliation provides an increase in the incident radiation at the level of clusters. The accumulation of soluble solids is related to the solar radiation available at the level of clusters - the higher the radiation available, the higher the accumulation of soluble solids.
\end{abstract}

Key words: total soluble solids, defoliation, conduction system trellis, balance shortwave.

A quantidade de radiação solar que penetra no dossel vegetativo é de grande importância para a videira, pois além de influenciar o desenvolvimento da planta e a síntese de compostos orgânicos, melhora a produção e a qualidade da uva (Mandelli et al., 2008; SMART, 1985). Em razão das características inerentes a cada sistema de condução da videira, como a distribuição e a orientação da folhagem dentro do dossel, a captação e a penetração da radiaçáo solar realizam-se de forma diferenciada (NorberTo et al., 2009).
A penetração da radiação solar no dossel vegetativo favorece a iniciaçáo floral, a fertilidade da gema, o pegamento do fruto e a maturação da uva (CARbonneau, 1982).

A exposição dos cachos à radiação solar está relacionada a maior acúmulo de sólidos solúveis, sendo maiores os teores de açúcares nos frutos quanto maior for a intensidade de radiação solar incidente (TeIXEIRA, 2004). ABE et al. (2007) relataram que o acúmulo de açúcar é o fenômeno mais importante da maturação, não somente pela quantidade de 
álcool que dele deriva, mas também por ele servir de origem para outros compostos, como os polifenóis, as antocianinas e aqueles relacionados ao aroma.

O sistema de condução em pérgola, também conhecido como latada, empregado com frequência nos vinhedos da serra gaúcha, produz grandes valores de superfície foliar (Norberto et al., 2008), podendo reduzir a quantidade de radiação interceptada pelos cachos. Modificaçôes no sistema de condução da videira e no manejo do cultivo induzem alteraçóes no microclima do vinhedo (Pedro Júnior et al., 2007; 2011). Nesse sentido, práticas de manejo, como a data da poda seca e a realização da desfolha, são estratégias que interferem na quantidade de radiação disponível à videira.

Ao comparar sistemas de condução em Y e em espaldeira durante safras de inverno e de verão em Jundiaí, SP, PEDro JúNIOR et al. (2013) observaram que as maiores diferenças entre os valores de radiação solar global medidos na altura dos cachos e a radiação solar global acima do dossel foram obtidas para a espaldeira durante a safra de inverno $\left(10,6 \mathrm{MJ} \mathrm{m}^{-2} \mathrm{dia}^{-1}\right)$ e de verão $\left(14,6 \mathrm{MJ} \mathrm{m}^{-2} \operatorname{dia}^{-1}\right)$.

A época de poda seca interfere na relação entre o desenvolvimento fenológico e as condiçóes do tempo ao longo do ciclo da cultura, uma vez que a data de poda passa a ser a referência para o início do ciclo fenológico da videira, sofrendo a influência das condições meteorológicas predominantes durante aquele período (LeÃo e SiLva, 2003). A desfolha, quando empregada, pode provocar grandes alteraçôes no dossel vegetativo, permitindo maior incidência da radiação solar no interior dele (Giovaninni, 2008).

Outro condicionante da quantidade de radiação solar disponível ao nível dos cachos é a quantidade de radiaçáo que é refletida pelo dossel, que é caracterizada pelas condiçóes de reflexibilidade da superfície. A quantidade de radiação refletida varia, em uma mesma cultura, com o estádio fenológico. Isso foi observado em videiras cultivar Itália, nas quais AzEvedo et al. (1997) verificaram que o albedo médio diário variou de 0,18 , nos primeiros dias após a brotação das gemas, a 0,23 após a floraçấo, reduzindo-se para 0,20 no período de desenvolvimento dos frutos.

Os objetivos do presente trabalho foram determinar a influência da realização da desfolha e da época da poda seca sobre o albedo da videira e sobre a radiação solar disponível ao nível dos cachos e determinar o efeito da disponibilidade de radiação solar ao nível dos cachos no acúmulo de sólidos solúveis.

O experimento foi desenvolvido em uma propriedade agrícola familiar, localizada no oitavo distrito de Pelotas, RS ( $31^{\circ} 30^{\prime} \mathrm{S}, 52^{\circ} 34^{\prime} \mathrm{O}$ e a $122 \mathrm{~m}$ altitude), durante o ano agrícola de 2010/2011. Os dados foram coletados em videiras da cultivar Bordô, pé franco, conduzidas em sistema pérgola com espaçamento de $3 \times 2 \mathrm{~m}$, respectivamente, na entrelinha e na linha. As entrelinhas foram mantidas cobertas durante todo o ciclo fenológico com as forrageiras aveia preta (Avena sp.), azevém (Lolium sp.), trevo (Trifolium sp.) e brachiaria (Brachiaria sp.).

Foram avaliadas duas épocas de poda seca, mantendo-se varas com cinco a seis gemas (poda longa), sendo também as plantas submetidas ou não a poda verde. Os tratamentos de poda seca foram: época normal, realizada no dia 14 de setembro, e época tardia, realizada dia 29 de setembro. Sobre uma parcela das plantas podadas na época normal e na época tardia foi realizada a desfolha (poda verde), no dia 26 de novembro, quando as plantas encontravam-se com os cachos no estádio de chumbinho, segundo a classificação fenológica proposta por EICHHORN e LoRenz (1984). Com a poda verde foram removidas todas as folhas abaixo da inserção do primeiro cacho do ramo. Esse nível de desfolha vem sendo adotado nos trabalhos de autores como AnZANello et al. (2011) e MANDELli et al. (2008).

Os tratamentos avaliados foram: NC; NS; TC; TS, onde a primeira letra refere-se à época de realização da poda seca $(\mathrm{N}=$ normal, $\mathrm{T}=$ tardia $)$ e a segunda letra representa a desfolha $(\mathrm{C}=$ com, $\mathrm{S}=\mathrm{sem})$.

$\mathrm{Na}$ colheita, em cada tratamento, foi avaliado o teor de sólidos solúveis (SS) das bagas por um refratômetro manual de campo. Para isso foram realizadas amostragens em cinco plantas por tratamento, coletando-se aleatoriamente três bagas de cinco cachos por planta de cada tratamento.

A radiação solar incidente no nível dos cachos ( $\mathrm{Ri})$, a radiação refletida pelo dossel da videira $(\mathrm{Rr})$ e a radiação solar global (Rs) foram medidas por tubos solarímetros de construção artesanal. Para medir a radiação solar global (Rs), os tubos foram posicionados acima do dossel da videira, com o elemento sensor voltado para cima; também acima do dossel, com o sensor voltado para baixo, para a medir a radiação refletida $(\mathrm{Rr})$; e posicionado abaixo do dossel da cultura, com o elemento sensor voltado para cima, a fim de medir-se a radiação interceptada ao nível dos cachos (Ri). Os valores medidos de radiação solar (global, refletida e interceptada) foram integralizados diariamente, obtendo-se as respectivas radiaçóes totais diárias, que foram convertidas em MJ m${ }^{-2}$ dia $^{-1}$. Os dados de radiação interceptada ao nível dos cachos do tratamento NS náo serão apresentados devido a dano nesse sensor, não sendo possível sua substituição no campo.

Os dados obtidos foram agrupados em valores diários para cada variável, sendo que o coeficiente de refletividade do cultivo à radiação solar global, o albedo $(\alpha)$, foi obtido pela equação:

$\alpha=\frac{\mathrm{Rr}}{\mathrm{Rs}}$

Para análise dos dados de radiação e sólidos solúveis foi usado delineamento inteiramente casualizados com três tratamentos, sendo eles NC, TS e TC, com três repetiçóes. Realizou-se análise de variância, seguida de teste de média a 5\% de significância. 
Os resultados de refletividade do dossel da videira demonstraram que o comportamento do albedo é variável ao longo do ciclo (Figura 1). Quando a poda foi realizada em época normal e com desfolha (NC), o albedo aumentou de 0,26, no dia 3/dez., para 0,33 , no dia $1 /$ jan. Essa variação, ao longo do ciclo, está associada ao visível aumento da cobertura foliar da videira registrado entre as datas analisadas, sendo esse um dos responsáveis pela alteração do coeficiente de refletividade. Esses valores superam aqueles obtidos por AzEvedo et al. (1997) que, ao trabalhar com videiras cultivar Itália, verificou que o albedo médio diário variou de 0,18 , nos primeiros dias após a brotação das gemas, a 0,23 , após a floraçáo, reduzindo-se para 0,20 no período de desenvolvimento dos frutos.

A realização da poda seca exerceu influência sobre o albedo, sendo o maior valor observado na época normal e sem desfolha (NS), com diferença presente até meados de janeiro, como consequência do crescimento vegetativo, o que levou à uniformizaçáo do dossel vegetativo e, por consequência, à estabilização do albedo (Figura 1). Para os tratamentos que receberam a desfolha (NC e TC), foi verificada tendência semelhante aos tratamentos sem desfolha, entretanto a diferença entre as épocas de poda seca foi menos pronunciada.

Na Figura 1 é possível verificar o efeito da desfolha sobre os valores de albedo: essa prática de manejo, quando realizada no final de novembro, permitiu a maior penetração da radiação solar no dossel, diminuindo, por conseguinte, os valores do albedo até meados de janeiro, tanto no tratamento com poda normal como no com poda tardia. O albedo médio, para o período compreendido entre a desfolha e a colheita, foi $0,29,0,28,0,30$ e 0,29 para NC, TC, NS e TS, respectivamente.

A partir da quantidade de radiação solar disponível ao nível dos cachos (Figura 2), é possível constatar que essa apresenta relação inversa com a radiação solar refletida (Figura 1), já que, nas fases inicias, quando o albedo apresentava baixos valores (menor cobertura foliar), a RScachos foi elevada. Notou-se ainda que a partir de janeiro houve estabilizaçáo na quantidade de RScachos, em função da estabilização da cobertura foliar (Figura 2), fato também verificado para os valores de albedo (Figura 1). Isto corrobora os resultados obtidos por Teixeira e Lima Filho (1997) em Petrolina, PE, que, ao avaliarem a relação entre o índice de área foliar e a radiação solar na cultura da videira, observaram decréscimo da transmissão de radiação solar até 60 dias após a poda, acompanhando o aumento do índice de área foliar - a partir de então, esses parâmetros tenderam a estabilizarem-se. A prática da desfolha provocou alteraçóes na quantidade de RScachos (Figura 2), verificando-se menor quantidade de radiação solar disponível ao nível dos cachos no tratamento que náo recebeu a desfolha (TS), quando comparado ao tratamento com desfolha (TC), corroborando os dados do albedo (Figura 1), em que o TS apresentou o maior albedo. Quando o albedo é maior resta menor quantidade de radiação disponível para ser utilizada pela planta, pois para Schöffel e Volpe (2000), o albedo, caracterizado como a fração da radiação incidente que é devolvida à atmosfera pelas condiçôes de reflexibilidade da superfície terrestre, é um componente importante do balanço de energia.

A maior disponibilidade de radiaçáo ao nível dos cachos em funçấo da desfolha foi permitida pela eliminação das folhas

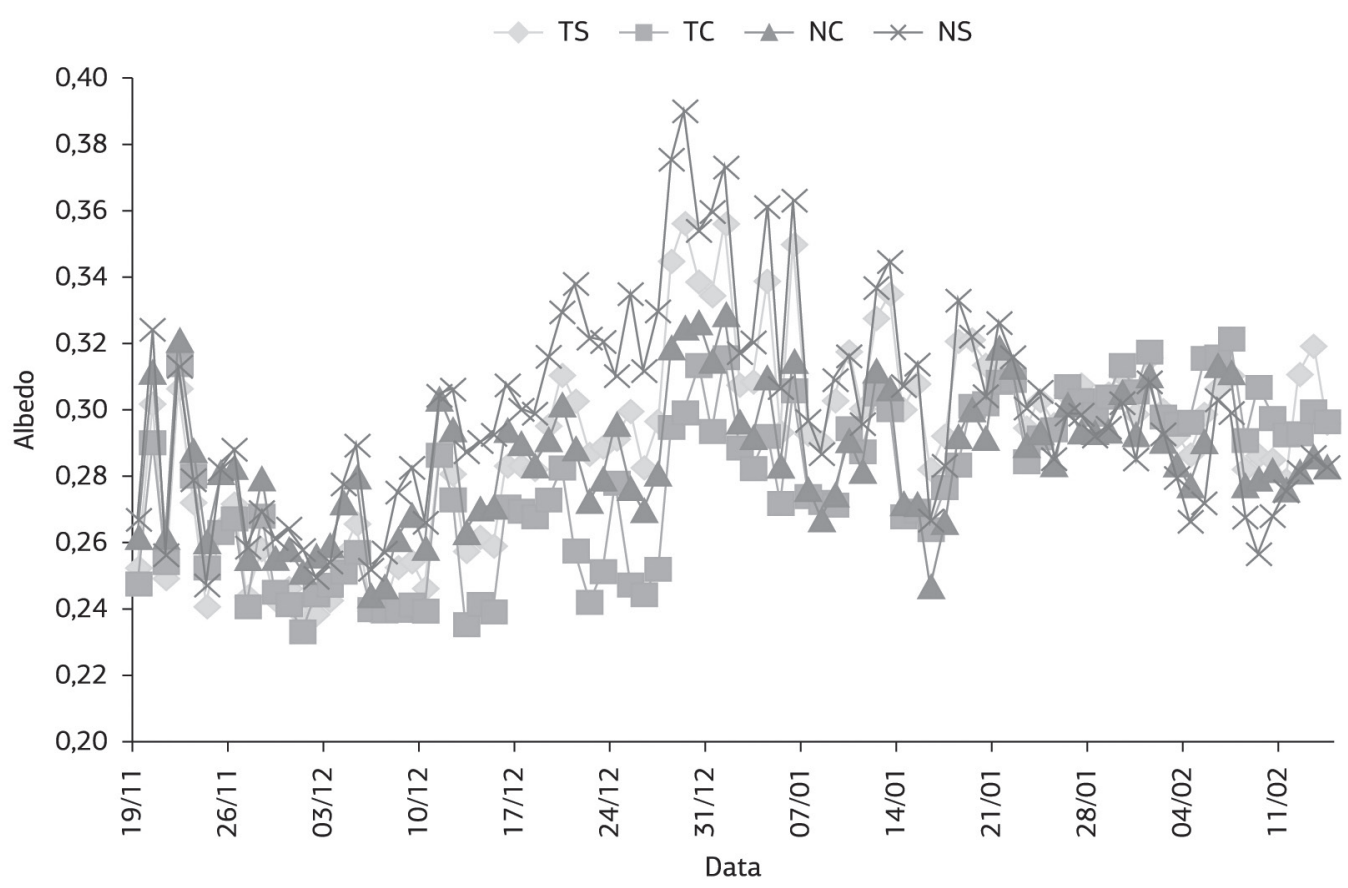

Figura 1. Valores diários do albedo de um vinhedo da cultivar Bordô conduzida no sistema pérgula durante a safra 2010/2011 em Pelotas, RS. 


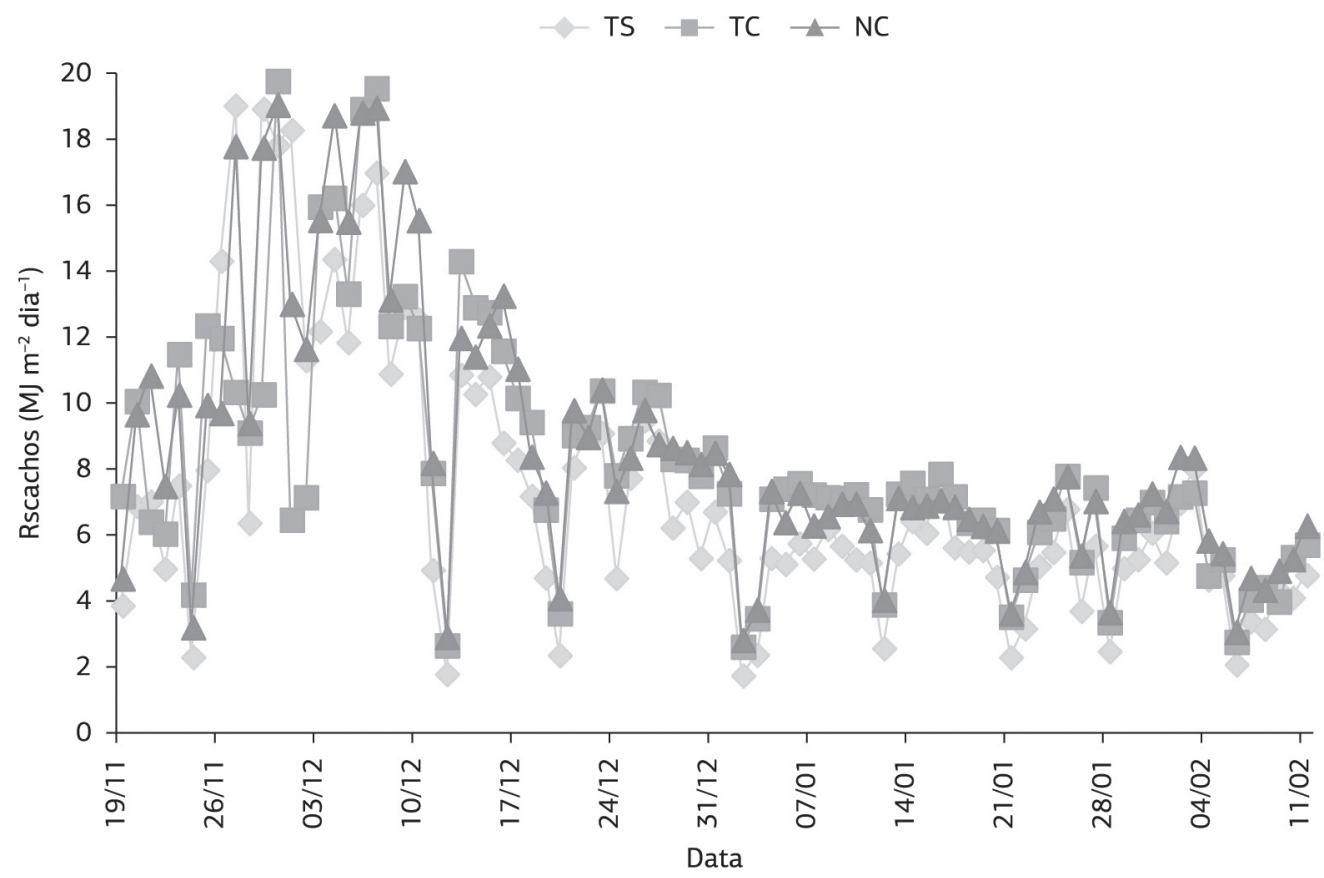

Figura 2. Radiação solar disponível ao nível dos cachos (RScachos) na cultivar Bordô conduzida no sistema em pérgula durante a safra 2010/2011 em Pelotas, RS.

próximas aos cachos, o que possibilitou maior penetração da radiação no interior do dossel vegetativo do vinhedo. Isso é sustentado por Giovaninni (2008) e corrobora os resultados obtidos por ChavarRia et al. (2010) que, ao compararem dois ciclos de cultivo em uvas Moscato Giallo, verificaram maior disponibilidade de radiação para os cachos quando a desfolha foi mais severa. Ainda, durante os meses de novembro e dezembro, Pedro Júnior et al. (2007) observaram que a radiação ao nível dos cachos para os sistemas em espaldeira e em manjedoura foi em torno de $14 \%$ (espaldeira) e de $24 \%$ (manjedoura) da radiação solar global disponível, enquanto que a partir de janeiro ocorreu transmissão de radiação solar mais elevada no sistema em espaldeira, cerca de $17 \%$ a $23 \%$, quando comparada ao sistema em manjedoura (12\% a 15\%). Os autores atribuíram essa diferença à desfolha, que deixou os cachos da espaldeira mais expostos à radiaçáo solar, por serem os ramos conduzidos verticalmente, enquanto na manjedoura são inclinados.

De modo semelhante ao comportamento verificado para o albedo, a época de realização da poda seca também não proporcionou grande diferença na quantidade de RScachos (Figura 2). Para o período comprendido entre a desfolha e a colheita, a maior disponibilidade média de radiação solar ao nível dos cachos e o maior teor de sólidos solúveis foram obtidos nos tratamentos com desfolha (Tabela 1), o que demonstra a relação existente entre essas duas variáveis. Verifica-se na Tabela 1 que maiores valores de RScachos proporcionam maiores teores de sólidos solúveis (SS).

A associação entre o teor de SS e a RScachos também foi observada por OrLANDO et al. (2003) que, ao estudarem
Tabela 1. Radiação solar disponível ao nível dos cachos (RScachos) para o período compreendido entre a desfolha e a colheita dos frutos e sólidos solúveis (SS) presentes na colheita para a cultivar Bordô conduzida no sistema em pérgula durante a safra 2010/2011 em Pelotas, RS

\begin{tabular}{ccc} 
Tratamento & $\begin{array}{c}\text { RScachos } \\
\text { (M) } \mathbf{~ m}^{-2} \mathbf{~ d i a}^{-1} \text { ) }\end{array}$ & $\begin{array}{c}\text { SS } \\
\left({ }^{\circ} \text { Brix }\right)\end{array}$ \\
\hline NC & $8,60 a$ & $16,7 a$ \\
\hline TC & $8,14 b$ & $16,3 b$ \\
\hline TS & $7,26 \mathrm{c}$ & $15,5 \mathrm{c}$ \\
\hline
\end{tabular}

Médias seguidas de letras distintas, na coluna, diferem entre si pelo teste de Tukey a $5 \%$ de significância

a caracterização agronômica de cultivares de videira (Vitis labrusca L.) em diferentes sistemas de condução, obtiveram valores de sólidos solúveis superiores nos sistemas espaldeira e lira e associaram o maior teor de SS acumulado à maior incidência da radiação solar na regiấo dos cachos. Para Camargo et al. (2010) e Maia e Camargo (2005), a cultivar Bordô, em média, apresenta entre 15,3 e $16^{\circ}$ Brix, variando com as condiçóes climáticas e de manejo de cada safra.

Observando-se os tratamentos TC e TS na Tabela 1, verifica-se que a desfolha altera a qualidade dos frutos, provocando aumento no SS. Associa-se esse aumento a maior incidência de radiaçáo sobre os cachos (RScachos) permitida pela desfolha pois, conforme afirmam PEDro Júnior et al. (2007), sistemas de conduçáo da videira que permitem maior interceptação da radiação solar são, geralmente, mais eficientes na obtenção da melhor qualidade da produção. 
Esses resultados estão em concordância com aqueles obtidos por Hunter et al. (1991) que, trabalhando com videiras Cabernet Sauvignon em Nearstellenbosch, constataram que a desfolha propiciou mostos com maior teor de sólidos solúveis e que, de maneira geral, os vinhos obtidos a partir dos vinhedos com desfolha apresentaram qualidade superior se comparados aos obtidos de videiras com tratamento sem desfolha. Para videira cultivada sob cobertura plástica, Chavarria et al. (2010) observaram decréscimo na taxa de incremento de açúcares ao longo da maturação, resultado atribuído à menor incidência de radiação ao nível dos cachos, pois a cobertura restringiu em até $56 \%$ essa radiação.

A realização da poda seca exerce influência sobre o albedo da videira Bordô e os maiores valores são observados quando a poda seca ocorre na época normal e sem desfolha. $\mathrm{O}$ adiamento da poda seca representa redução na quantidade de radiação solar disponível ao nível dos cachos e a realização da desfolha propicia aumento na radiação que incide ao nível dos cachos. $\mathrm{O}$ acúmulo de sólidos solúveis apresenta relação positiva com a radiação solar disponível ao nível dos cachos.

\section{REFERÊNCIAS}

ABE, L.T.; MOTA, R.V.; LAJOLO, F.M.; GENOVESE, M.I. Compostos fenólicos e capacidade antioxidante de cultivares de uvas Vitis labrusca L. e Vitis vinifera L. Ciência e Tecnologia de Alimentos, v.27, p.394-400, 2007. http://dx.doi.org/10.1590/S010120612007000200032

ANZANELLO, R.; SOUZA, P.V.D.; COELHO, P.F. Desfolha em videiras americanas e viníferas na fase de pré-maturação dos frutos. Ciência Rural, v.41, p.1132-1135, 2011. http://dx.doi.org/10.1590/ S0103-84782011005000080

AZEVEDO, P.V.; TEIXEIRA, A.H.C.; SILVA, B.B.; SOARES, J.M.; SARAIVA, F.A.M. Avaliação da reflectância e do saldo de radiação sobre um cultivo de videira européia. Revista Brasileira de Agrometeorologia, v.5, p.1-7, 1997.

CAMARGO, U.A.; MAIA, J.D.G.; RITSCHEL. Embrapa Uva e Vinho novas cultivares brasileiras de uva. Bento Gonçalves: Embrapa uva e vinho, 2010. 64p.

CARBONNEAU, A. Apports biologiques récents à l'étude des systèmes de conduite. Bulletin de l'O.I., v.55, p.273-285, 1982.

CHAVARRIA, G.; SANTOS, H.P.; ZANUS, M.C.; MARODIN, G.A.B.; CHALAÇA, M.Z.; ZORZAN, C. Maturação de uvas Moscato Giallo sob cultivo protegido. Revista Brasileira de Fruticultura, v.32, p.151-160, 2010. http://dx.doi.org/10.1590/ S0100-29452010005000014

EICHHORN, K.W.; LORENZ, D.H. Phaenologische Entwicklungsstadien der Rebe. European and Mediterranean Plant Protection Organization, v.14, p.295-298, 1984.

GIOVANINNI, E. Produção de uvas para vinhos, suco e mesa. 3. ed. Porto Alegre: Renascença, 2008. 364p.

HUNTER, J.J.; VILLIERS, O.T.; WATTS, J.E. The effect of partial defoliation on quality characteristics of Vitis vinifera L. cv. 'Cabernet
Sauvignon' grapes. II. Skin sugar, and wine quality. American Journal of Enology and Viticulture, v.42, p.13-18, 1991.

LEĀO, P.C.S.; SILVA, E.E.G. Caracterização fenológica e requerimentos térmicos de variedades de uvas sem sementes no Vale do São Francisco. Revista Brasileira de Fruticultura, v.25, p.379-382, 2003. http:// dx.doi.org/10.1590/S0100-29452003000300004

MAIA, J.D.G.; CAMARGO, U. A.. Sistema de Produção de Uvas Rústicas para Processamento em Regióes Tropicais do Brasil. Bento Gonçalves: Embrapa Uva e Vinho, 2005. (Sistemas de produção, n.9)

MANDELLI, F.; MIELE, A.; RIZZON, L.A.; ZANUS, M.C. Efeito da poda verde na composição físico-química do mosto da uva Merlot. Revista Brasileira de Fruticultura, v.30, p.667-674, 2008. http:// dx.doi.org/10.1590/S0100-29452008000300018

NORBERTO, P.M.; REGINA, M.A.; CHALFUN, N.N.J.; SOARES, A.M.; FERNANDES, V.B.; GAJEGO, E.B. Superfície foliar da videira 'Folha de Figo' e 'Niagara Rosada' conduzida em diferentes sistemas de condução. Ciência e Agrotecnologia, v.32, p.1866-1871, 2008. http://dx.doi.org/10.1590/S1413-70542008000600027

NORBERTO, P.M.; REGINA, M.A.; CHALFUN, N.N.J.; SOARES, A.M. Efeito do sistema de condução em algumas características ecofisiológicas da videira (Vitis labrusca L.). Ciência e Agrotecnologia, v.33, p.721-726, 2009. http://dx.doi.org/10.1590/ S1413-70542009000300009

ORLANDO, T.G.S.; REGINA, M.A.; SOARES, A.M.; CHALFUN, N.N.J.; SOUZA, C.M.; FREITAS, G.F.; TOYOTA, M. Caracterização agronômica de cultivares de videira (vitis labrusca L.) em diferentes sistemas de condução. Ciência e Agrotecnologia, v.27, p.721-726, 2003.

PEDRO JÚNIOR, M.J.; HERNANDES, J.L.; BLAIN, G.C.; ROLIM, G.S. Microclima em vinhedos de 'Niagara rosada' em diferentes sistemas de condução durante safras de inverno e de verão. Revista Brasileira de Fruticultura, v.35, p.151-158, 2013. http://dx.doi.org/10.1590/ S0100-29452013000100018

PEDRO JÚNIOR, M.J.; HERNANDES, J.L.; ROLIM, G.S. Sistema de condução em Y com e sem cobertura plástica: microclima, produção, qualidade do cacho e ocorrência de doenças fúngicas na videira 'Niagara Rosada'. Bragantia, v.70, p.228-233, 2011. http:// dx.doi.org/10.1590/S0006-87052011000100030

PEDRO JÚNIOR, M.J.; HERNANDES, J.L.; TECCHIO, M.A.; PEZZOPANE, J.R.M. Influência do sistema de condução no microclima, produtividade e qualidade de cachos da videira Niagara Rosada, em Jundiaí (SP). Revista Brasileira de Fruticultura, v.29, p.313317, 2007. http://dx.doi.org/10.1590/S0100-29452007000200024

SCHÖFFEL, E.R.; VOLPE, C.A. Albedo e balanço de radiação da superfície de uma cultura de soja durante o período reprodutivo. Científica, v.28, p.103-114, 2000.

SMART, R.E. Principles of grapevine canopy microclimate manipulation with implications for yield and quality: a review. American Journal of Enology and Viticulture, v.36, p.230-239, 1985.

TEIXEIRA, A.H.C.; LIMA FILHO, J.M.P. Relações entre o índice de área foliar e radiação solar na cultura da videira. Revista Brasileira de Agrometeorologia, v.5, p.143-146, 1997.

TEIXEIRA, A.H.C. Cultivo da Videira. Embrapa Semi-Árido, 2004. (Sistemas de produção, n.1). 